\title{
Testosterone in COVID-19 \\ - Foe, Friend or Fatal Victim?
}

\author{
Sanjay Kalra, ${ }^{1}$ Saptarshi Bhattacharya ${ }^{2}$ and Atul Kalhan ${ }^{3}$ \\ 1. Department of Endocrinology, Bharti Hospital, Karnal, India; 2. Department of Endocrinology, Max Hospital, New Delhi, India; \\ 3. Department of Endocrinology, Royal Glamorgan Hospital, Cardiff, UK
}

DOl: https://doi.org/10.17925/EE.2020.16.2.88

$\mathrm{T}$ he evidence derived from observational studies suggests male gender, diabetes and central obesity to be risk factors associated with an increased COVID-19-related case fatality. The precise pathophysiology behind this gender difference in mortality outcomes remains unclear at this stage, although it is worth exploring a possible role of testosterone as one of the contributory factors. The observed role of androgens in transcription of transmembrane protease serine-2, which facilitates COVID-19 anchoring to angiotensin-converting enzyme 2 cell surface receptors, seems to suggest that higher testosterone levels might be detrimental for outcomes. On the other hand, men with type 2 diabetes mellitus and central obesity have an increased prevalence of hypogonadotropic hypogonadism, with inhibition of gonadotropin-releasing hormone secretion induced by inflammatory cytokines being one of the postulated mechanisms. The increased COVID-19 case fatality in this cohort might perhaps reflect an underlying pro-inflammatory state, with low testosterone levels being either a surrogate marker of a poor metabolic state or playing a more active role in propagation of inflammation and thrombosis.

\section{Keywords}

COVID-19, SARS-CoV-2, testosterone

Disclosures: Sanjay Kalra, Saptarshi Bhattacharya and Atul Kalhan have no financial or non-financial relationships or activities to declare in relation to this article. Sanjay Kalra is a member of the journal's Editorial Board.

Review Process: Double-blind peer review.

Compliance with Ethics: This article is an opinion piece and does not report on new clinical data, or any studies with human or animal subjects performed by any of the authors.

Authorship: The named authors meet the International Committee of Medical Journal Editors (ICMJE) criteria for authorship of this manuscript, take responsibility for the integrity of the work as a whole, and have given final approval for the version to be published.

Access: This article is freely accessible at touchENDOCRINOLOGY.com (c) Touch Medical Media 2020.

Received: 29 April 2020

Accepted: 21 July 2020

Published Online: 6 October 2020

Citation: European Endocrinology. 2020;16(2):88-91

Corresponding Author: Sanjay Kalra,

Department of Endocrinology, Bharti Hospital, Kunjpura

Road, Model Town, Karnal 132001, Haryana, India.

E: bridekn|@gmail.com

Support: No funding was received in

the publication of this article.
The role of testosterone is well established in health and disease. ${ }^{1}$ Testosterone is known to mediate physical, mental and reproductive health. Its role has been discussed in gender-specific variations related to conditions as diverse as cardiovascular, autoimmune, psychiatric and oncological diseases. ${ }^{2-4}$ The recent coronavirus disease 2019 (COVID-19) pandemic has uncovered newer facets of testosterone action and dysfunction. This editorial discusses recent evidence to answer the question: is testosterone a foe, friend or fatal victim of COVID-19?

\section{Testosterone as a foe}

Epidemiological data from China and Europe describe higher incidence of COVID-19 in men, compared with women. ${ }^{5,6} \mathrm{~A}$ meta-analysis of 39 observational studies has reported an increased proportion of men $(57.4 \%$; 8,518/14,844) who required hospitalization due to COVID-19 infection compared with women.? Although socio-cultural factors could partially explain this epidemiological difference, a disproportionately higher predisposition for men to develop serious COVID-19-related complications requires further evaluation. Out of the total number of patients who were admitted to intensive care units, $81 \%$ were men $(1,345 / 1,661)$. Similarly, case fatality was higher in men compared with women (men, $n=394$; women, $n=218$ ). ${ }^{7}$ Several other studies have also reported higher mortality rates among men., ${ }^{8,9}$ The various hypotheses which have been postulated to explain the male predisposition to severe COVID-19 infection are summarised in Table 1.10-21 The exact pathophysiology behind the gender gradient observed in COVID-19 infection, however, remains unclear.

To enter the pneumocytes, COVID-19 must anchor to the angiotensin-converting enzyme 2 (ACE2) cell surface receptor. This process is facilitated by proteolytic priming of the viral spike proteins present in COVID-19. This priming is done by an enzyme known as transmembrane protease serine-2 (TMPRSS2). ${ }^{22}$ The transcription of TMPRSS2 is promoted by androgens that act through the 15 bp androgen response element present in the human TMPRSS2 gene. ${ }^{23}$ Androgen receptor activity is essential for TMPRSS2 expression and, in fact, is its only identified promoter in humans, and might explain the predominance and severity of COVID-19 observed in men. ${ }^{24}$

It has been suggested that alternative mechanisms might be driving the gender differential outcomes observed in COVID-19 infection. One hypothesis states that the poor outcomes seen in men might be mediated by dihydrotestosterone, and worsened by 5- $\alpha$ reductase inhibitors, attributed to disruption of intrapulmonary androgen metabolism. ${ }^{25}$ Androgen receptor polymorphisms, which are often ethnically determined, have also been suggested to be linked to the differences in case-fatality rate observed in African-American and Caucasian men. ${ }^{26}$ Androgenic alopecia is a surrogate marker of androgen activity. Spanish observers have reported a high prevalence of visually confirmed androgenic alopecia in patients admitted with COVID-19 infection. ${ }^{27}$ 
Table 1: Hypotheses explaining male predisposition to severe COVID-19

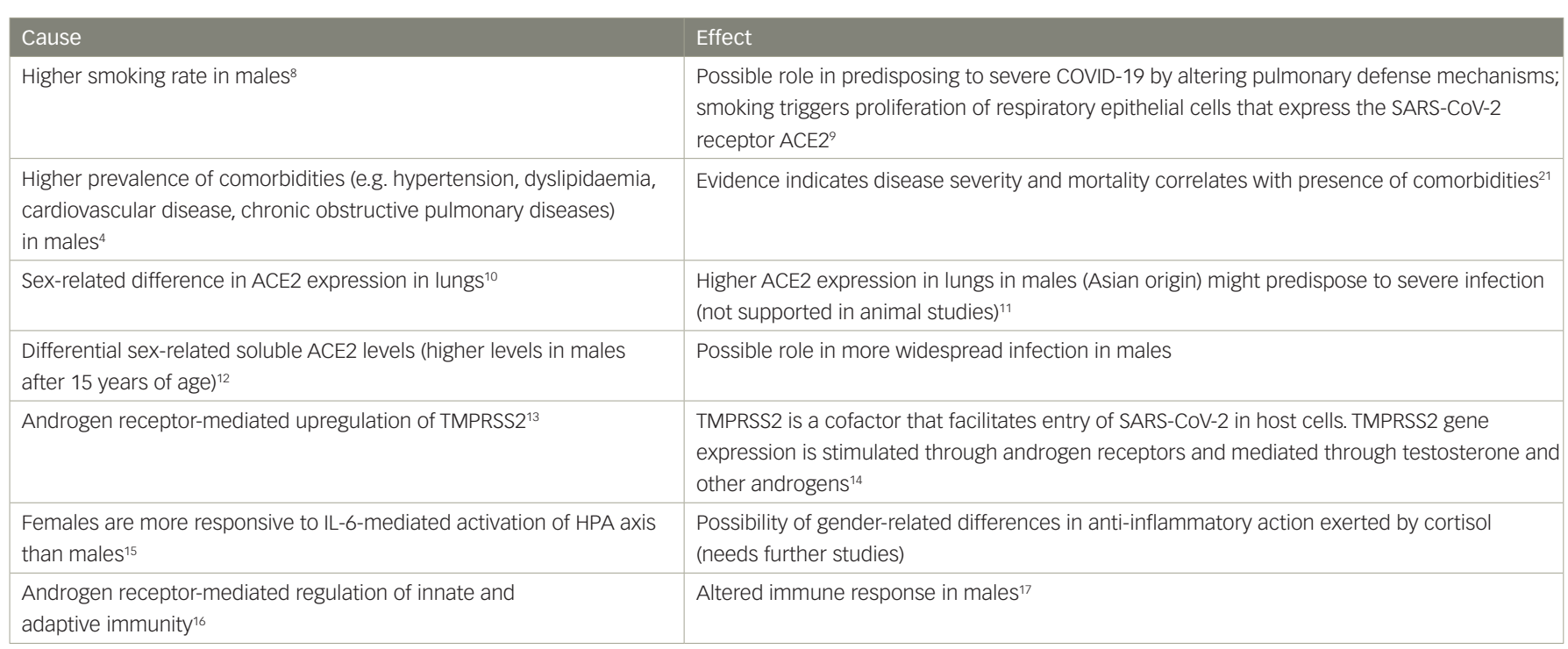

ACE2 = angiotensin-converting enzyme 2; HPA = hypothalamic-pituitary-adrenal; lL-6 = interleukin 6; SARS-Cov-2 = severe acute respiratory syndrome coronavirus 2; TMPRSS2 = transmembrane protease serine- 2 .

They also hypothesise the role of anti-androgen therapy in attenuating the symptoms of COVID-19. Chloroquine and nitric oxide, both of which are being studied as therapies for COVID-19, are known to reduce testosterone in animal models, ${ }^{28}$ and inhibit androgen receptor activity in prostate cancer, ${ }^{29}$ respectively.

The anti-inflammatory effects of dexamethasone in treatment of hospitalised patients with COVID-19 have been under the spotlight after the announcement of preliminary results from the multicentric RECOVERY (Randomised Evaluation of COVid-19 thERapY) trial in the United Kingdom. The initial results suggest low-dose dexamethasone could decrease mortality in critically ill patients requiring oxygen or mechanical ventilation. ${ }^{30}$ The endogenous cortisol response after COVID-19 is also robust..$^{31}$ Serum cortisol levels might act as a surrogate marker of severe infection, but can also be the body's adaptive response to suppress inflammation. Thus, both endogenous and exogenous corticosteroids might have a protective role in severe COVD-19 infection. In 2007, Jankord et al. reported a gender-related difference in hypothalamic-pituitary-adrenal (HPA) response to stress, mediated by interleukin-6 (IL-6), with female pigs showing higher adrenocorticotropic hormone secretion in comparison to male pigs. ${ }^{18}$ We propose that the differential HPA axis response to IL-6 (a key mediator of cytokine storm in COVID-19 infection) ${ }^{32}$ could be a possible mechanism accounting for the gender disparity and this concept requires further evaluation.

The androgen-driven COVID-19 pandemic theory may emerge as a plausible hypothesis to explain the complex relationship between COVID-19 and testosterone. ${ }^{33}$ Based upon this theory, testosterone appears to be a promoter of COVID-19 infection, and as such, a foe of 'man'kind. Although no data have been published yet, it would be interesting to study the natural history of COVID-19 in female hyperandrogenic states such as polycystic ovary syndrome and congenital adrenal hyperplasia. A retrospective study of seven pregnant women infected with COVID-19 has observed the presence of polycystic ovary syndrome in two of them, although no inferences can be drawn from this small sample size. ${ }^{34}$

\section{Testosterone as a friend}

The poor outcomes associated with COVID-19 infection are often linked to cytokine release syndrome. Cytokine release syndrome is a severe systemic inflammatory response to viral infection, which is mediated by $\mathrm{IL}-6 .{ }^{35}$ COVID-19 is found to affect the older age group disproportionately. ${ }^{5-7}$ It is also noteworthy that IL-6 concentrations are higher in elderly populations, which is partly attributed to low levels of testosterone. ${ }^{36}$

Another noteworthy observation is the increased COVID-19 case fatality in the presence of comorbidities (non-gonadal illness), which are often associated with hypogonadotropic hypogonadism state in men. These include metabolic conditions such as diabetes and obesity, and physiological states of low testosterone in elderly men. ${ }^{5-7,37}$ A meta-analysis of observational studies suggests that the low endogenous testosterone in elderly males predicts cardiovascular mortality and morbidity. ${ }^{38}$ Testosterone modulates calcium-mediated contraction of cardiac myocytes. ${ }^{39}$ Studies report a sex-related difference in cardiac contractility, as handling of calcium may be influenced by sex steroids. ${ }^{40}$ It is well known that cardiovascular diseases contribute to mortality in COVID-19, especially in men. ${ }^{5-7,41}$ The impact of low testosterone levels in men on cardiovascular disease and its further influence on mortality in COVID-19 could be an interesting research proposition.

Testosterone replacement reduces inflammatory response and IL-6 levels in hypogonadal men. In a crossover study of 27 men with symptomatic androgen deficiency, testosterone supplementation reduced levels of proinflammatory tumour necrosis factor alpha (TNF- $\alpha$ ), IL-1 $\beta$, and $I L-6$, as well as increased concentration of the anti-inflammatory cytokine, IL-10. ${ }^{42}$ Another study of 69 men with stable coronary artery disease revealed a significant inverse correlation between testosterone and IL-1 $\beta$ across the spectrum of eugonadal, borderline hypogonadal and hypogonadal men. ${ }^{43}$ Testosterone is also documented to protect murine models from severe influenza by attenuating the proinflammatory cytokine response in lung tissue. ${ }^{44}$ 
These data, though not directly related to COVID-19, suggest that testosterone might have a protective role (as a much-needed friend) in the fight against the infection.

Testosterone supplementation has been linked with venous thromboembolism and pulmonary embolism.45 On the other hand, male hypogonadism is a prothrombotic state and testosterone supplementation might have a protective role. ${ }^{46}$ Endothelial nitric oxide production, a potent inhibitor of platelet activation, is enhanced by testosterone and might safeguard against thrombotic tendency. ${ }^{47}$ In case of hypogonadism, as observed in elderly men, or in presence of comorbidities, the antithrombotic effect might be lost. ${ }^{47} \mathrm{~A}$ pro-thrombotic tendency plays a major role in aggravating morbidity and mortality in COVID-19 infection, which may further be worsened in the presence of a hypogonadal state..$^{20,48}$

\section{Testosterone as a fatal victim}

Severe acute respiratory syndrome coronavirus 2 (SARS-CoV-2; COVID-19) is primarily a respiratory pathogen; however, its impact is seen across virtually every organ system. Many severe acute respiratory syndrome (SARS) viruses have been shown to cause orchitis. ${ }^{27}$ Pathological findings include destruction of germ cells, apoptosis of spermatogenic cells, near-absence of spermatozoa in the seminiferous epithelium, thickening of basement membrane, and infiltration of leucocytes. ${ }^{49}$ Viral particles have been identified in seminiferous tubular epithelium and Leydig cells, suggesting that the gonadal dysfunction is testicular, rather than pituitary/hypothalamic in nature. ${ }^{50}$ The ACE2, which serves as the receptor for entry of COVID-19 into target cells, is expressed in testicular tissue including spermatogonia, Leydig cells and Sertoli cells. TMPRSS2 is found in spermatogonia and spermatids as well. ${ }^{51}$ It is noteworthy that the highest expression level of ACE2 protein among all organs is in the testes, along with the intestine, gall bladder and kidney. ${ }^{52}$

It is possible that the leucocytic infiltration of the testes can lead to production of interferons, which inhibit local steroidogenesis, including testosterone production, and destroy the seminiferous epithelium. ${ }^{21}$ As the blood-testes barrier is pervious to COVID-19, the virus may reach the male reproductive tract. This may be a potential source of spread of infection, as has been noted with other viruses. ${ }^{53}$ As of now, however, there is no evidence of viral transmission through semen of males recovering from COVID-19. ${ }^{54}$

Apart from the anatomical findings, biochemical studies also point towards gonadal dysfunction in COVID-19-infected males. In a study of 81 such men, the testosterone:luteinizing hormone ratio was significantly reduced compared with healthy age-matched controls. Serum prolactin and luteinizing hormone levels were higher in the COVID-19 cohort. Serum testosterone:luteinizing hormone ratio showed significant inverse association with C-reactive protein as well. ${ }^{55}$ This suggests a testicular pathology, which may be inflammatory in character. Testosterone synthesis and secretion, therefore, may be a fatality of COVID-19 infection.

The effect of COVID-19 infection on male fertility has not been reported to date. A recent publication from China reported that SARS-COV-2 was not detected by quantitative real-time polymerase chain reaction in semen of 34 COVID-19-infected males after a median interval of 31 days. Six (19\%) of these patients reported a history of scrotal discomfort during the acute phase of infection which could be related to orchitis. ${ }^{54}$

\section{Summary}

COVID-19 is an unprecedented global health crisis, and our understanding of the disease is evolving at a rapid pace. The close and complex relationship between testosterone and COVID-19 needs further investigation. The data from preliminary observational studies are suggestive of an increased COVID-19-related case fatality in men with central obesity and diabetes mellitus. ${ }^{56}$ This raises the question of whether the low testosterone levels in such men can be used as a surrogate indicators of poor metabolic health and can be used as a prognostic marker. The biological plausibility of the pre-morbid hypogonadal state predisposing such men to worse COVID-19 outcome warrants further research, especially considering that therapeutic interventions are available to improve testosterone levels and this relatively simple measure can potentially improve the clinical outcome. ${ }^{36}$ Besides elaboration of the role of ACE2 and TMPRSS2 in facilitating entry of the virus into the cell and their intricate relation to androgen pathway, they may also unravel newer pathophysiological links and therapeutic opportunities. $]$
1. Saad F, Roehrig G, von Haehling S, Traish A. Testosterone deficiency and testosterone treatment in older men. Gerontology. 2017; 63:144-56.

2. Quang $\mathrm{LM}$, Kalhan A. Cardiovascular benefits and risks of testosterone replacement therapy in hypogonadal men with type 2 diabetes mellitus and/or the metabolic syndrome: a systematic review. Br J Diabetes. 2018;18:141-6.

3. Baillargeon J, Snih SA, Raji MA, et al. Hypogonadism and the risk of rheumatic autoimmune disease. Clin Rheumatol. the risk of rheumatic

4. Ruth KS, Day FR, Tyrrell J, et al. Using human genetics to understand the disease impacts of testosterone in men and women. Nat Med. 2020;26:252-8.

5. Guan WJ, Ni ZY, Hu Y, et al. Clinical characteristics of coronavirus disease 2019 in China. N Eng/ J Med. 2020;382:1708-20.

6. Remuzzi A, Remuzzi G. COVID-19 and Italy: what next? Lancet. 2020;395:1225-8.

7. Espinosa OA, Zanetti ADS, Antunes EF, et al. Prevalence of comorbidities in patients and mortality cases affected by SARS-COV2: a systematic review and meta-analysis. Rev Inst Med Trop Sao Paulo. 2020;62:e43.

8. Onder G, Rezza G, Brusaferro S. Case-fatality rate and characteristics of patients dying in relation to COVID-19 in Italy. JAMA. 2020;323:1775-6.

9. Sun YJ, Feng YJ, Chen J, et al. Clinical features of fatalities in patients with COVID-19. Disaster Med Public Health Prep. 2020; doi:10.1017/dmp.2020.235 [Online ahead of publication].

10. Bailer J, Kerstner T, Witthöft M, et al. Health anxiety and hypochondriasis in the light of DSM-5. Anxiety Stress Coping. 2016;29:219-39.

11. Cai H. Sex difference and smoking predisposition in patients with COVID-19. Lancet Respir Med. 2020;8:e20.

12. Smith JC, Sausville EL, Girish V, et al. Cigarette smoke triggers the expansion of a subpopulation of respiratory epithelial cells that express the SARS-COV-2 receptor ACE2. Dev Cell.
2020;53:514-29.

13. Zhao Y, Zhao Z, Wang $Y$, et al. Single-cell RNA expression profiling of ACE2, the receptor of SARS-COV-2. Am J Respir Crit Care Med. 2020;202:756-9.

14. Xudong X, Junzhu C, Xingxiang W, et al. Age- and gender-related difference of ACE2 expression in rat lung. Life Sci. 2006;78:2166-71.

15. Swärd P, Edsfeldt A, Reepalu A, et al. Age and sex differences in soluble ACE2 may give insights for COVID-19. Crit Care. 2020;24:221

16. Lucas JM, True L, Hawley S, et al. The androgen-regulated type II serine protease TMPRSS2 is differentially expressed and mislocalized in prostate adenocarcinoma. J Pathol. 2008;215:118-25.

17. Lin B, Ferguson C, White JT, et al. Prostate-localized and androgen-regulated expression of the membrane-bound serine protease TMPRSS2. Cancer Res. 1999;59:4180-4.

18. Jankord R, Turk JR, Schadt JC, et al. Sex difference in link between interleukin-6 and stress. Endocrinology. 2007;148:3758-64.

19. Lai J-J, Lai K-P, Zeng W, et al. Androgen receptor influences on body defense system via modulation of innate and adaptive immune systems: lessons from conditional AR knockout mice. immune systems: lessons from
Am J Pathol. 2012;181:1504-12.

20. Giagulli VA, Guastamacchia E, Magrone T, et al. Worse progression of COVID-19 in men: Is testosterone a key factor? Andrology. 2020; doi:10.1111/andr.12836 [Online ahead of publication]

21. Hedger MP, Meinhardt A. Cytokines and the immune-testicular axis. J Reprod Immunol. 2003;58:1-26

22. Hoffmann M, Kleine-Weber H, Schroeder S, et al. SARS-CoV-2 cell entry depends on ACE2 and TMPRSS2 and is blocked by a clinically proven protease inhibitor. Cell. 2020;181:271-80.e8

23. Lucas JM, Heinlein C, Kim T, et al. The androgen-regulated protease TMPRSS2 activates a proteolytic cascade involving components of the tumor microenvironment and promotes prostate cancer metastasis. Cancer Discov. 2014;4:1310-25.

24. Stopsack KH, Mucci LA, Antonarakis ES, et al. TMPRSS2 and COVID-19: Serendipity or opportunity for intervention? Cancer Discov. 2020;10:779-82

25. Adamowicz J, Juszczak K, Drewa T. May patients receiving 5-alpha-reductase inhibitors be in higher risk of COVID-19 complications? Med Hypotheses. 2020;140:109751.

26. van Dorn A, Cooney RE, Sabin ML. COVID-19 exacerbating inequalities in the US. Lancet. 2020;395:1243-4.

27. Goren $A$, Vano-Galvan $S$, Wambier $C G$, et al. A preliminary Goren A, Vano-Galvan S, Wambier CG, et al. A prelimina
observation: male pattern hair loss among hospitalized COVID-19 patients in Spain-a potential clue to the role of androgens in COVID-19 severity. J Cosmet Dermatol. 2020;19:1545-7

28. Nicola WG, Khayria MI, Osfor MMH. Plasma testosterone level and the male genital system after chloroquine therapy. Boll Chim Farm. 1997;136:39-43.

29. Cronauer MV, Ince $Y$, Engers $R$, et al. Nitric oxide-mediated inhibition of androgen receptor activity: possible implications for prostate cancer progression. Oncogene. 2007;26:1875-84

30. RECOVERY Collaborative Group, Horby P, Lim WS, et al. Dexamethasone in hospitalized patients with COVID-19 Dexamethasone in hospitalized patients with COVID-19

31. Tan T, Khoo B, Mills EG, et al. Association between high serum total cortisol concentrations and mortality from COVID-19. Lancet Diabetes Endocrinol. 2020;8:659-60.

32. MCGonagle D, Sharif K, O'Regan A, Bridgewood C. The role of cytokines including interleukin-6 in COVID-19 induced pneumonia and macrophage activation syndrome-like disease. Autoimmun Rev. 2020;19:102537.

33. Kezele TG. Androgen-driven COVID-19 infection - is testosterone an enemy or a friend? Horm Mol Biol Clin Investig. 2020;41:/j/hmbci.2020.41.issue-2/hmbci-2020-0027/ hmbci-2020-0027.xml. 
34. Yu N, Li W, Kang Q, et al. Clinical features and obstetric and neonatal outcomes of pregnant patients with COVID-19 in Wuhan, China: a retrospective, single-centre, descriptive study. Lancet Infect Dis. 2020;20:559-64.

35. Ye Q, Wang $B$, Mao J. The pathogenesis and treatment of the 'cytokine storm' in COVID-19. J Infect. 2020;80:607-13.

36. Nash SD, Cruickshanks KJ, Klein R, et al. Long-term variability of inflammatory markers and associated factors in a population-based cohort. J Am Geriatr Soc. 2013;61:1269-76.

37. Pivonello R, Menafra D, Riccio E, et al. Metabolic disorders and male hypogonadotropic hypogonadism. Front Endocrinol (Lausanne). 2019;10:345

38. Corona G, Rastrelli G, Di Pasquale G, et al. Endogenous testosterone levels and cardiovascular risk: meta-analysis of observational studies. J Sex Med. 2018;15:1260-71.

39. Ayaz O, Howlett SE. Testosterone modulates cardiac contraction and calcium homeostasis: cellular and molecula mechanisms. Biol Sex Differ. 2015;6:9.

40. Parks RJ, Howlett SE. Sex differences in mechanisms of cardiac excitation-contraction coupling. Pflugers Arch. 2013;465:747-63.

41. Aggarwal G, Cheruiyot I, Aggarwal S, et al. Association of cardiovascular disease with coronavirus disease 2019 (COVID-19) severity: a meta-analysis. Curr Probl Cardiol. 2020;45:100617.

42. Malkin CJ, Pugh PJ, Jones RD, et al. The effect of testosterone replacement on endogenous inflammatory cytokines and lipid profiles in hypogonadal men. J Clin Endocrinol Metab. 2004;89:3313-8.

43. Nettleship JE, Pugh PJ, Channer KS, et al. Inverse relationship between serum levels of interleukin- $1 \beta$ and testosterone in men with stable coronary artery disease. Horm Metab Res. 2007;39:366-71.

44. Tuku B, Stanelle-Bertram S, Sellau J, et al. Testosterone protects against severe influenza by reducing the pro-inflammatory cytokine response in the murine lung. Front Immunol. 2020;11:697.

45. Houghton DE, Alsawas M, Barrioneuvo P, et al. Testosterone therapy and venous thromboembolism: A systematic review therapy and venous thromboembolism: A systema
and meta-analysis. Thromb Res. 2018;172:94-103.

46. Carlioglu A, Durmaz SA, Kibar YI, et al. Mean platelet volume in a patient with male hypogonadotropic hypogonadism: the relationship between low testosterone, metabolic syndrome, impaired fasting glucose and cardiovascular risk. Blood coagul Fibrinolysis. 2015;26:811-5.

47. Ajayi AA, Mathur R, Halushka PV. Testosterone increases human platelet thromboxane $\mathrm{A} 2$ receptor density and aggregation responses. Circulation. 1995;91:2742-7.

48. Al-Ani F, Chehade S, Lazo-Langner A. Thrombosis risk associated with COVID-19 infection. A scoping review. Thromb Res. 2020;192:152-60.

49. Xu J, Qi L, Chi X, et al. Orchitis: a complication of severe acute respiratory syndrome (SARS). Biol Reprod. 2006;74:410-6.
50. Zhao JM, Zhou GD, Sun YL, et al. Clinical pathology and pathogenesis of severe acute respiratory syndrome. Zhonghua Shi Yan He Lin Chuang Bing Du Xue Za Zhi. 2003;17:217-21.

51. Wang $Z, X u X$. scRNA-seq profiling of human testes reveals the presence of the ACE2 receptor, a target for SARS-COV-2 infection in spermatogonia, Leydig and sertoli cells. Cells. 2020;9:920.

52. Hamming I, Timens W, Bulthuis ML, et al. Tissue distribution of ACE2 protein, the functional receptor for SARS coronavirus A first step in understanding SARS pathogenesis. $J$ Pathol. 2004;203:631-7.

53. Salam AP, Horby PW. The breadth of viruses in human semen Emerg Infect Dis. 2017;23:1922-4.

54. Pan $F$, Xiao $X$, Guo J, et al. No evidence of severe acute respiratory syndrome-coronavirus 2 in semen of males recovering from coronavirus disease 2019. Fertil Steril. 2020;113:1135-9.

55. Ma L, Xie W, Li D, et al. Evaluation of sex-related hormones and semen characteristics in reproductive-aged male COVID-19 patients. J Med Virol. 2020; doi:10.1002/jmv.26259 [Online ahead of print].

56. Holman N, Knighton P, Kar P, et al. Risk Factors for COVID-19 mortality in people with Type 1 and Type 2 diabetes in England: a population-based cohort study Lancet Diabetes Endocrinol: 2020;8:823-3. 